\title{
RETROSPECTIVE ANALYSIS OF ACHIEVEMENTS OF WOMEN WEIGHTLIFTERS AT THE OLYMPIC GAMES
}

\author{
V. Panayotov*, N. Yankova \\ National Sports Academy „Vasil Levski“, Sofia, Bulgaria
}

\begin{abstract}
PURPOSE: Women's Olympic weightlifting became a part of the program of the Olympic Games at the 2000 Olympics in Sydney, Australia. The Bulgarian weightlifting school has been very successful in preparing elite female weightlifters since its very introduction. This review aimed to assess and rank the results of the Bulgarian female weightlifters at the Olympic Games held between 2000 and 2016. METHODS: Rankings of the Bulgarian female weightlifters at the Olympic Games were analyzed and compared by both absolute weight and values corrected by the Sinclair coefficient.

RESULTS: A positive trend in results for both competitive movements was found. Results in the clean and jerk were better on average than those in the snatch. We consider the higher performances of female weightlifters measured in the weight class of $69 \mathrm{~kg}$ as an indicator of evolution in their results during recent years.

CONCLUSIONS: The Bulgarian school in women's Olympic weightlifting established a tradition in preparing elite weightlifters during the last 18 years. To preserve this positive trend, coaches should base the sports selection process for young female weightlifters on scientific grounds.
\end{abstract}

Key words: weightlifting, sports performances, Bulgarian weightlifters, snatch, clean and jerk

\section{INTRODUCTION}

Women's weightlifting officially became a part of the Olympics program at the Olympic Games in Athens in 2000. The Bulgarian Weightlifting School is well acknowledged for imposing standards for successful performance at major competitions over the years. In this article, we studied the performance of the Bulgarian female weightlifters between 2000 and 2016. Their results at the Olympic Games were analyzed and compared in both absolute values and Sinclair coefficients. We found an ascending trend in the results of our athletes in this most respected international event $(1,2)$. The popularity of women's participation in the Olympic movement always provoked a great public interest regarding developing and promoting women's sports in general. Athletes' pursuit of high sports results and their successful participation in the Olympic Games increase the significance of women's sport

\footnotetext{
*Correspondence to: Valentin Panayotov, National Sports Academy ,, Vasil Levski “, Weightlifting, boxing, fencing and sport for all, 1700, Sofia, Studentski grad, E-mail: v_panajotov@abv.bg,Mobile:00359893396440
}

internationally (3-5). Globally, women's weightlifting was first established as an organized sport discipline back in $1987(6,7)$. In our opinion, we do not have to exhaustively analyze world record statistics to access the evolution of women's records: it is enough to compare only some figures from the early years of women's Olympic weightlifting $(8,9)$. In 1996, the International Olympic Committee voted to accept women's weightlifting in the Olympic family and the first Olympic contest in women's weightlifting took place in Sydney in 2000. In recent years, the Bulgarian Weightlifting Federation has been attempting to do everything possible to provide the best training conditions for elite female weightlifters. The increase in the number of women actively practicing this sport and the improvement in the quality of training inspired researchers to study the performance of both the most successful Bulgarian lifters and recreational athletes $(10,11)$.

With the present study we aimed to analyze the performance and rankings of the Bulgarian female weightlifters on the Olympic Games held between 2000 and 2016. 


\section{METHODOLOGY}

We set the following objectives:

1. To study rankings of the Bulgarian lifters at the Olympic Games.

2. To measure the ratio between successful and unsuccessful attempts of the Bulgarian weightlifters at the Olympic Games.

3. To determine how successful our athletes' attempts were at the Olympic Games.

4. To compare the performance data from the Olympic Games according to the Sinclair point system in some weight classes.

5. To evaluate sports achievements at the Olympic Games according to the Sinclair coefficient system.

Subjects of our study were female weightlifters aged 21-34 who had participated in the Olympic Games held between 2000 and 2016. We performed a systemic-structural analysis of women's weightlifting protocols for the period. To correctly compare the achievements of female weightlifters during this period, we applied calculations based on the Sinclair coefficient as gives an accurate and realistic picture of the development of their strength abilities by correcting the data with body mass values $(12,13,14)$.

\section{RESULTS AND ANALYSIS}

The Bulgarian weightlifters participated in three of five Olympic Games held from 2000 to $2016(15,16,17,18)$. Bulgaria was involved in several doping scandals in this sport in recent years and this was one of the reasons for our lifters to omit two Olympic Games during this period: the adverse effects of these events will be never be overcome by the Bulgarian athletes. 85 weightlifters from 47 countries participated at the Olympic Games in Sydney, 2000. The Bulgarian athletes had won quotas for four competitors (the maximum number permitted): I. Rifatova, D. Mincheva, D. Kerkelova, and M. Trendafilova.

Isabella Rifatova won the first Olympic title for women in the history of the world weightlifting but unfortunate circumstances deprived her of the medal in the weight class of $48 \mathrm{~kg}$. Due to the consequences of an unfolding doping scandal, she was stripped from her gold medal. Our next competitor, D. Mincheva, pursuing a medal, did several fouls and left the competition. Bulgarians however, won their first points in women's weightlifting at the Olympics games: M. Trendafilova ranked fourth and D. Kerkelova - fifth.
Milena Trendafilova's results follow:

Snatch - 1 successful $(100.0 \mathrm{~kg})$ and 2 unsuccessful attempts (105.0 kg) - a $33.33 \%$ success rate.

Clean \& Jerk - 2 successful $(127.5 \mathrm{~kg}$ and $132.5 \mathrm{~kg})$ and 1 unsuccessful attempt (132.5 $\mathrm{kg})$ - a $66.67 \%$ success rate.

Overall - 3 successful and 3 unsuccessful attempts - a total of $232.5 \mathrm{~kg}$, and a success rate of $50 \%$. Denoted in Sinclair points 263.17 .

Results of Daniela Kerkelova:

Snatch -2 successful $(97.5 \mathrm{~kg}$ and $100.0 \mathrm{~kg})$ and 1 unsuccessful attempts $(100.0 \mathrm{~kg})-\mathrm{a}$ $66.67 \%$ success rate.

Clean \& Jerk - 2 successful $(127.5 \mathrm{~kg}$ and $132.5 \mathrm{~kg}$ ) and 1 unsuccessful attempts (132.5) - a $66.67 \%$ success rate.

Overall - 4 successful and 2 unsuccessful attempts - a total of $232.5 \mathrm{~kg}$, and a success rate of $66.67 \%$. Denoted in Sinclair points 262.35 .

Obviously, the success rate of D. Kerkelova was higher. When Sinclair coefficients were compared, we found a tie in absolute results and a 0.82 higher Sinclair score for $\mathrm{M}$. Trendafilova. The total success rate of our participants at the Olympic Games was measured at $25.93 \%$ (including the unsuccessful attempts of D. Mincheva). Data for I. Rifatova were excluded due to the stripped medal.

In 2004, at the Olympic Games in Athens, Greece, the number of female weightlifters remained unchanged but four fewer countries participated. The Bulgarian female weightlifters took part with full quotas but could not win a medal in any weight class. Compared to the previous Games, although the competition was strong, our weightlifters achieved similar success. Three Bulgarian contestants were ranked among the top six: 21year-old S. Rujinska took the fourth place, and three veterans in women's weightlifting, 33year-old I. Rifatova, 34-year-old $M$. Trendafilova, and Z. Atanasova ranked fifth, sixth, and twelfth respectively.

Results of Isabella Rifatova:

Snatch -2 successful $(80.0 \mathrm{~kg}$ and $82.5 \mathrm{~kg}$ ) and 1 unsuccessful attempts $(85.0 \mathrm{~kg})-\mathrm{a}$ $66.67 \%$ success rate.

Clean \& Jerk - 2 successful $(100.0 \mathrm{~kg}$ and $105.0 \mathrm{~kg})$ and 1 unsuccessful attempts $(105.0$ $\mathrm{kg})$ - a $66.67 \%$ success rate. 
Overall - 4 successful, 2 unsuccessful attempts - a total of $187.5 \mathrm{~kg}$ and a success rate of $66.67 \%$. (274.81 in Sinclair points).

Results of Zlatina Atanasova:

Snatch - 1 successful $(90.0 \mathrm{~kg})$ and 2 unsuccessful attempts $(95.0 \mathrm{~kg})$ - a $33.33 \%$ success rate.

Clean \& Jerk - 1 successful $(115.0 \mathrm{~kg})$ and 2 unsuccessful attempts (125.0kg) - a $33.33 \%$ success rate. Overall -2 successful, 4 unsuccessful attempts - a total of $205.0 \mathrm{~kg}$ and a success rate of $33.33 \%$. Denoted in Sinclair points -256.36 .

Results of Milena Trendafilova:

Snatch -1 successful $(105.0 \mathrm{~kg})$ and 2 unsuccessful attempts $(107.5 \mathrm{~kg})$ - a $33.33 \%$ success rate.

Clean \& Jerk -2 successful $(130.0 \mathrm{~kg}$ and $132.5 \mathrm{~kg})$ and 1 unsuccessful attempts (130.0 $\mathrm{kg})$ - a $66.67 \%$ success rate).

Overall -3 successful and 3 unsuccessful attempts - a total of $237.5 \mathrm{~kg}$ ans a success rate of 50\%/ 267.79 Sinclair points.

Results of Slaveika Rujinska:

Snatch -2 successful (110.0kg and $115.0 \mathrm{~kg}$ ) and 1 unsuccessful attempts $(115.0 \mathrm{~kg})-\mathrm{a}$ $66.67 \%$ success rate.

Clean \& Jerk - 1 successful $(135.0 \mathrm{~kg})$ and 2 unsuccessful attempts $(142.5 \mathrm{~kg}$ and $145.0 \mathrm{~kg})-$ a $33.33 \%$ success rate.

Overall - 3 successful, 3 unsuccessful attempts - a total of $250.0 \mathrm{~kg}$ and a success rate is $50 \%$.

Denoted in Sinclair points - 281.88.

The highest success rate was achieved by I. Rifatova and the lowest - by S. Rujinska. S. Rujinska realized an outstanding result of 281.88 Sinclair points, followed by $M$. Trendafilova with 267.79. Most probably, the low success rate of S. Rujinska was due to the grate weights she was adding to the barbell in every successive attempt in her struggle for medals. At the 2004 Olympic Games, we achieved a total success rate of $50 \%$, which is $24.07 \%$ higher compared to the previous Olympics.

At the Olympic Games in 2008 in Beijing, the Bulgarian team did not participate (irrespective of the two quotas our athletes had gained) as 3 female weightlifters were accused of doping
PANAYOTOV V., et al.

usage during their preparation: Milka Maneva, Donka Mincheva and Gergana Kirilova.

At the next Olympic Games in London in 2012, only one Bulgarian lifter, Milka Maneva, participated and was ranked 5th. Four years later, in 2016, it was announced that the top three competitors in the weight class of $63 \mathrm{~kg}$ were officially disqualified after they tested positive for anabolic steroids. This automatically ranked M. Maneva second and she became the first Olympic medallist in the history of Bulgarian women's weightlifting.

Results of Milka Maneva:

Snatch -2 successful (98.0kg and $102.0 \mathrm{~kg}$ ) and 1 unsuccessful attempts (105.0kg) $66.67 \%$ success rate.

Clean \& Jerk -2 successful $(125.0 \mathrm{~kg}$ and $131.0 \mathrm{~kg})$ and 1 unsuccessful attempts (134.0 $\mathrm{kg})-66.67 \%$ success rate.

Overall - 4 successful and 2 unsuccessful attempts - a total of $233.0 \mathrm{~kg}$ and a success rate of 66.67\%/275.93 Sinclair points: M. Maneva achieved a success rate of over $50 \%$, and a high Sinclair coefficient.

After this success, due to a new doping scandal in 2015 our athletes were not allowed to participate in big championships and this hurt Bulgarian weightlifting badly. Once again, the Bulgarian weightlifters were banned for the 2016 Olympic Games in Rio de Janeiro due to numerous violations of anti-doping rules.

For the analyzed period, Bulgarian female weightlifters won one silver medal, two fourth, two fifth and one sixth places at Olympic Games:

1. Milka Maneva - 2nd place (silver medal)

2. Milena Trendafilova - IV-th and VI-th place

3. Slaveika Ruzhinka - IV-th place

4. Daniela Kerkelova - V-th place

5. Isabela Rifatova - V-th place

Since the debut of the Bulgarian female weightlifters at the Olympic Games, the undisputed leader in the history of women's weightlifting from is Milka Maneva.

Figure 1 presents the average success rate of successful and unsuccessful attempts of the Bulgarian female weightlifters at the Olympic Games in percentage points. 


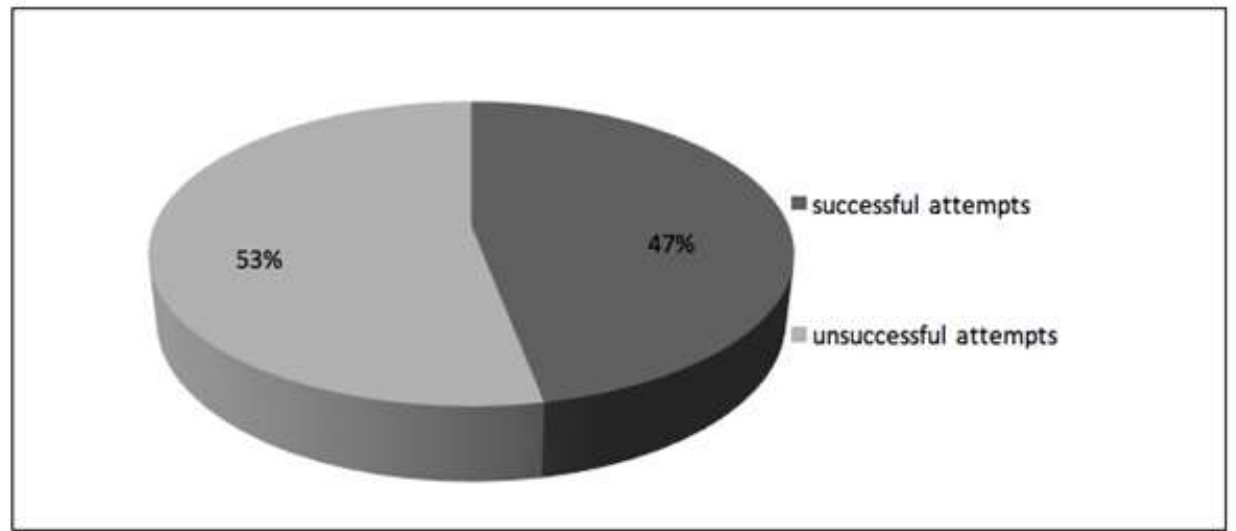

Figure 1. Percentage distribution of successful and unsuccessful attempts of the Bulgarian female weightlifters at the Olympic Games held between 2000 and 2016

The figure shows that our athletes made fewer successful attempts - $47 \%$ in both competitive exercises - a success rate of less than $50 \%$. Regarding individual competitive exercises, the success rate in the snatch was $54 \%$ and in the clean \& jerk $-46 \%$.

Compared to the clean and jerk, we found that in the snatch athletes used to add greater weights to the barbell for their successive attempts. This strategy (which was often passed unnoticed to coaches) is most probably one of the reasons behind the great number of unsuccessful attempts they realized. According to P. Dobrev, the number of unsuccessful attempts of elite athletes participating at the Olympic Games is an indicator of tactical training mistakes $(19,20)$. Our previous studies also corroborate these findings. Several tactical mistakes can potentially cause the world's strongest female weightlifters to be defeated at big competitions, among them: underestimation of the competitive situation in its entirety (due to psychological tension), overestimation of athlete's current shape and capabilities, lack of a concrete, realistic and flexible tactical strategy (regarding the weights the competitor should add to the bar in every successive attempt).

Figure 2 represents the average results of the Bulgarian female weightlifters in both competitive exercises (all attempts) for the studied period.

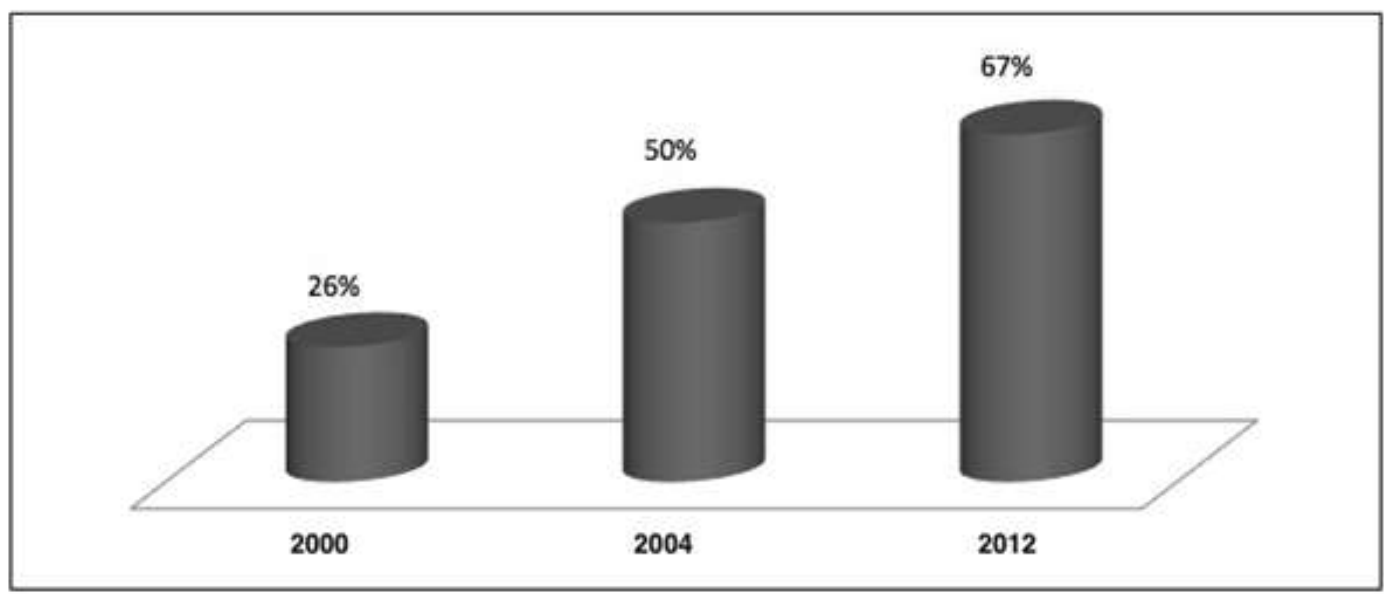

Figure 2. Percentage distribution of success rates of the Bulgarian female weightlifters for the analysed period

For the studied period, we found that the highest success rate was realized in 2012, and the lowest one - at the debut of women's weightlifting, the Olympic Games in 2000. To accurately evaluate and compare the performance of female weightlifters of different weight classes during this period we used the Sinclair coefficient. The highest
Sinclaire's score was achieved in 2012 275.93, and it was also supported by a high success rate. Although a weaker success rate (50\%) was realized in 2004, we found higher Sinclaire' result - 270.21 compared to this of the 2000 Olympics -262.76 . 
Below we present Sinclaire's points of the Bulgarian female weightlifters realized at the Olympic Games (Figure 3).

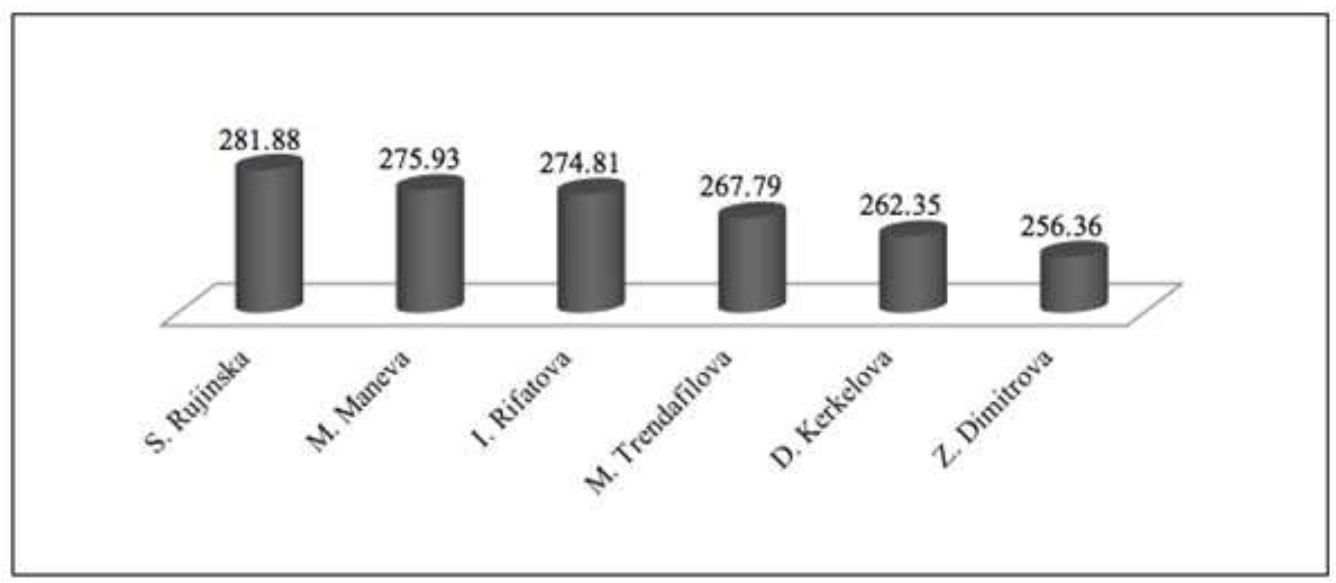

Figure 3. Sinclair points of the Bulgarian female weightlifters realized at the Olympic games held between 2000 and 2012

Analyzing the corrected data for the study period, we found that the highest score was achieved in 2004 by S. Rouzhinska, followed closely by M. Maneva, who were then the youngest participant of the Bulgarian team. M. Trendafilova increased her results for two consecutive Olympic Games (in the weight class of $69 \mathrm{~kg}$ ) by $5.0 \mathrm{~kg}$ - from $232.5 \mathrm{~kg}$ to $237.5 \mathrm{~kg}$. Compared to results of S. Rujinska (placed fourth in the next Olympic Games) the increase is $17.5 \mathrm{~kg}$ : in our opinion, this proves the existence of a rapid ascending trend in performance of the Bulgarian women's weightlifting.

\section{CONCLUSIONS}

Based on the analysis we derived the following conclusions:

1. During the studied period, the Bulgarian female weightlifters managed to compete pari passu with the most acknowledged nations in Olympic weightlifting: our athletes won one silver Olympic medal and six sixth places.

2. We found an overall ascending trend in performance in both competitive exercises with better results realized in the snatch compared to these in the clean and jerk.

3. We consider the higher Sinclaire's values found in the weight class of $69 \mathrm{~kg}$ as an indicator of an evolution in sports performance over the years.

4. We did not found a relation between success rate and Sinclaire' coefficient: the highest Sinclaire's coefficient -281.88 was realized by S. Rouzhinska, and the highest success rate $(67 \%)$ - by $M$. Maneva.

\section{REFERENCES}

1. Dimitrov, D., Vdiganeto na tegesti $v$ Bulgaria, Chast II. Stara Zagora, Shibilev, 2001

2. Dimitrov, D., Elita na balgarskite chtangisti, Abagar, Veliko Tarnovo, 2006.

3. Abramova, T., Ozolin, H., Geslevich, B., Savremenni predstavyania na nauchni trudove pri jeni. WORKSVNIIFK. Moskva, 1993.

4. Jordanskaya, F., Fizichesko vazpitanie i sport pri jeni. Moskva. Sovetski sport, 1995.

5. Miagkova, S., Fizichesko vazpitanie i sportno obuchenie. Teoria i praktika na fizicheskata kultura, 6:78-86, 2002.

6. Soboleva, T., Formation of the polyspecific characteristic of the girl and the child on the sports field, Dys. doc. biol. Science, 1997.

7. Robert, W., Women Move Closer to Olympic Equality, New York Times, Vol. 149, Iss. 51486, Sec. 1, Ch. 1, 2000.

8. Yankova, N., Sastoyanie i razvitie na sportno-technicheskite rezultati $\mathrm{v}$ jenskata tejka atletika, Sport i Nauka, 1:45-51, 2014.

9. Yankova, N., Poyava i razvitie na vdiganeto na tegesti pri jeni, Bolid Ins, Sofia, 2016.

10.Gyurkov, D., Vdigane na tejesti. Chast Parva, Typ-Top press, Uchebnik za studentite ot NSA, Sofia, 2005.

11.Gyurkov, D., Spasov, A., Vdigane na tejesti i silova trenirovka. ECDCCFFC, Sofia, 1979.

12. Sinclair's coefficient chart of the IWF. [Online], 2000, http://www.iwf.net/weightlifting_/sinclaircoefficient/. (Accessed 17 October 2018). 
13. Sinclair's coefficient chart of the IWF. [Online], 2004 , http://www.iwf.net/weightlifting_/sinclaircoefficient/. (Accessed 17 October 2018).

14. Sinclair's coefficient chart of the IWF. [Online], 2012, http://www.iwf.net/weightlifting_/sinclaircoefficient/. (accessed 17 October 2018).

15.Protocols of the IWF, [Online], 2000, https://en.wikipedia.org/wiki/Weightlifting _at_the_2000_Summer_Olympics. (accessed 17 October 2018).

16.Protocols of the IWF, [Online], 2004 https://en.wikipedia.org/wiki/Weightlifting
_at_the_2004_Summer_Olympics.

(accessed 17 October 2018).

17.Protocols of the IWF, [Online], 2012 https://en.wikipedia.org/wiki/Weightlifting _at_the_2012_Summer_Olympics. (accessed 17 October 2018).

18.Protocols of the IWF, [Online], 2016 https://en.wikipedia.org/wiki/Weightlifting _at_the_2016_Summer_Olympics. (accessed 17 October 2018).

19.Dobrev, P., Takticheska trenirovka na tejkoatletite, ETZNPKKKS, Sofia, 1983.

20.Dobrev, P., Gyurkov, D., Spasov A., Tejka atletika, MiF, Sofia, 1976. 